\title{
PARAGON-HF: Lessons Learned and Perspectives
}

\author{
José Francisco Kerr Saraiva ${ }^{1 \oplus}$ and Isadora de Oliveira ${ }^{2,3}{ }^{\oplus}$ \\ PUC-Campinas, ${ }^{1}$ Campinas, $S P$ - Brazil \\ Novartis Brasil - Medical Affairs, ${ }^{2}$ São Paulo, SP - Brazil \\ Universidade de São Paulo, ${ }^{3}$ São Paulo, SP-Brazil
}

An estimated 6.5 million Americans aged 20 and over have heart failure (HF) and projections show that the prevalence of $\mathrm{HF}$ will increase by $46 \%$ from 2012 to 2030, resulting in over 8 million people with HF. ${ }^{1}$

Patients with HF can be stratified into different categories of left ventricular ejection fraction (LVEF), presenting different phenotypes in terms of demographics, clinical presentation, etiology and outcomes. The current classification comprises $\mathrm{HF}$ with reduced ejection fraction (EF) $[\mathrm{EF} \leq 40 \%$ (HFrEF)], with intermediate EF [EF 40-50\% (HFiEF), and preserved EF [EF $\geq 50 \%$ (HFpEF). ${ }^{2,3}$

The diagnosis of HFpEF is challenging, starting with its definition and classification. The definition of HFpEF has evolved over the past two decades, from a primary focus on an echocardiographic evidence of diastolic dysfunction in the LVEF $\geq 50 \%$, moving towards a definition that includes (but is not limited to) cardiac structural abnormalities resulting from high filling pressures, diastolic abnormalities, high levels of biomarkers and high left ventricular (LV) filling pressures. ${ }^{2,3}$

The risk of HFpEF increases with age. Additional risk factors for the development of HFpEF include hypertension, obesity, and coronary artery disease. HFpEF and atrial fibrillation (AF) are age-related conditions that commonly coexist and share clinical features. At least one third of patients with HFpEF have AF. Therefore, the prevalence of HfpEF has increased with increasing age and epidemics of obesity, hypertension and diabetes. ${ }^{2,3}$

\section{Keywords}

Heart Failure/physiopathology; Neprilysin/therapeutic use; Echocardiography/methods; Dysfunction Left Ventricular/abnormalities; Indicators of Morbidity and Mortality; Risk Factors; Valsartan/therapeutic use.
HFpEF is associated with high morbidity and mortality. ${ }^{4}$ The survival of HFpEF is poor, particularly after hospitalization for HF. In a previous HFpEF epidemiology study, the survival of patients with HFpEF was $35 \%$ at 5 years after hospitalization for $\mathrm{HF}^{5}$

The prevalence of HFpEF ranges from 31\% to 55\%. Female gender is an important risk factor for the development of HfpEF, and the reason for this is not clear. However, women may have greater arterial and ventricular stiffness, which can be exacerbated with age. In addition, reproductive hormones may influence LV structure and function and on the response to overload changes. ${ }^{6}$

Another point to stress is that $\mathrm{HFpEF}$ is underdiagnosed in the general population. Differently from HFrEF where most of patients are diagnosed, in HFpEF there is a window of opportunities to improve clinical recognition and diagnosis. Recently, the $\mathrm{H}_{2} \mathrm{FPEF}$, a score based on simple clinical and echocardiographic features to estimate the likelihood of HFpEF among patients with unexplained dyspnea, has been developed. This score includes the following variables: obesity ( 2 points), $\geq 2$ antihypertensives ( 1 point), atrial fibrillation (3 points), pulmonary artery echocardiographic systolic pressure $>35 \mathrm{~mm} \mathrm{Hg}$ ( 1 point), age $\geq 60$ years (1 point) and echocardiogram $\mathrm{E} / \mathrm{e}^{\prime}>9$ (1 point). ${ }^{7}$

HFpEF, in addition to being a syndrome consisting of small left ventricle, significant concentric LV hypertrophy, normal EF, and diastolic dysfunction with reduced LV diastolic compliance, it is a multiorgan disease that involves not only the heart, but also the lungs, skeletal muscle, kidneys and adipose tissue. ${ }^{8}$

The pathophysiology of HFpEF is associated with systemic inflammation with subsequent reductions in biological functions of $\mathrm{NO}$ (nitric oxide), cyclic guanosine

Mailing Address: José Francisco Kerr Saraiva

Rua Oswaldo Oscar Barthelson, 1209 - Jardim Pauliceia. Postal Code: 13060-080, Campinas, SP - Brazil.

E-mail: jfsaraiva@uol.com.br 
monophosphate (cGMP) content, and protein activity associated with cardiomyocyte hypertrophy, as well as decreased titin protein phosphorylation, which increases passive stiffness. ${ }^{7}$

With respect to treatment, there is no specific treatment to reduce mortality associated with HFpEF. Despite the availability of multiple therapies to modify the prognosis in patients with reduced LVEF, to this day, no therapy has proven to reduce morbidity and mortality for patients with LVEF ( $\geq 40 \%)$.

HFpEF has been defined as a heterogeneous disease. For the past 20 years, no clinical trials involving therapeutic strategies focused on neurohormonal modulation (which have been proven successful in HFrEF patients) have been able to show clinical benefit for HFpEF patients. Drugs like irbesartan, perindopril, spironolactone and candesartan have failed to show statistically significant benefit compared with placebo. ${ }^{9-13}$

Possible explanations for the inaccurate diagnosis of HFpEF include the fact that the pathophysiology is not completely understood (with wrong mechanisms of action), non-optimal inclusion criteria or outcomes in the studies, geographical variations in the diagnosis and treatment of HFpEF, and type and frequency of comorbidities. The most probable hypothesis is that we have been treating a syndrome and not a disease anymore, and in fact, this syndrome is made up of a heterogeneous group of related diseases that may not respond to a single treatment approach.

Symptomatic treatment of HFpEF is empirical and consists mainly of diuretics used to reduce congestion, although there isn't enough data to support their use. Similarly, data about heart rate control in patients with atrial fibrillation, which is highly prevalent in HFpEF, are also limited. It is not yet clear whether rhythm control would be beneficial in patients with HFpEF and atrial fibrillation. ${ }^{14}$

Yet these trials have not evaluated the effect of neprilysin inhibition, and the beneficial cardiovascular effects of natriuretic peptides in this population. The angiotensin receptor-neprilysin inhibitor sacubitril/ valsartan resulted in a lower rate of hospitalization for HF or death from cardiovascular causes compared with enalapril among patients with HF and reduced LVEF $(\leq 40 \%)$ in the PARADIGM-HF trial. ${ }^{15}$ As for patients with HFpEF, sacubitril/valsartan resulted in a lower level of N-terminal pro-B-type natriuretic peptide, a larger reduction in left atrial size, and greater improvement in the NYHA functional class than valsartan in a phase II, randomized, placebo controlled clinical trial. ${ }^{16}$

The results of these two previous clinical trials provided the rational for the PARAGON-HF trial design. This was a phase III randomized, placebo controlled, event-driven trial designed to evaluate the safety and efficacy of sacubitril/valsartan compared to valsartan alone in patients with HF and preserved LVEF $(\geq 45 \%) .{ }^{17}$ The primary composite outcome of total hospitalizations for HF and death from cardiovascular causes did not differ significantly between the two groups. There were 894 primary events (690 hospitalizations for HF and 204 deaths from cardiovascular causes) in 526 patients in the sacubitril-valsartan group and 1,009 primary events (797 hospitalizations for HF and 212 deaths from cardiovascular causes) in 557 patients in the valsartan group (rate ratio, 0.87; $195 \%$ confidence interval [CI], 0.75 to $1.01 ; \mathrm{p}=0.06) .{ }^{18}$ Despite the results for the primary endpoint, the PARAGON-HF was a step closer to understanding HFpEF. Of the 12 prespecified subgroups, two showed possible heterogeneity of treatment effect. The findings suggested beneficial effects in patients with an EF lower than the median (57\%), and in women, who represented $52 \%$ of patients included in the final analysis. It is worth pointing out that the size of both subgroups was large enough for analysis (half the population in each subgroup). ${ }^{18}$

A secondary analysis of the PARAGON-HF has been recently published, ${ }^{19}$ revealing that, compared with valsartan, sacubitril/valsartan reduced the risk of HF hospitalization more in women than in men. On the primary outcome (total HF hospitalizations and cardiovascular death), there was a more favorable treatment effect in women than in men (rate ratio 0.73 [0.59-0.90] in women; 1.03 [0.84-1.25] in men; p interaction $=0.017$ ). Further analysis presented in this publication showed that this difference in effect was not explained by differences in the KCCQ questionnaire, NYHA class or renal outcomes. ${ }^{19}$

Another recent publication was a pre-specified pooled analysis of 13,195 patients from PARADIGM-HF (LVEF $\leq 40 \% ; \mathrm{n}=8,399)$ and PARAGON-HF (LVEF $\geq 45 \%$; $\mathrm{n}=4,796)$, two similarly designed pivotal clinical trials. Pooled data enabled an analysis of treatment effect across the continuum of LVEF.

Among the findings, rates of primary composite events decreased with increasing LVEF, with lower rates of cardiovascular death, mainly in patients with the highest LVEF compared with patients with the lower 
values. In addition, the therapeutic effects of sacubitril/ valsartan, compared with a renin-angiotensin system (RAS) inhibitor alone, vary across the continuum of LVEF, with the greatest benefits, especially for HF hospitalization, observed in patients with a LVEF below approximately $60 \%$. Therapeutic benefits of sacubitril/valsartan with respect to HF hospitalization and cardiovascular death are robust among patients with HFrEF; the PARAGON-HF data suggest that this benefit could be extended to patients with EF not frankly reduced (LVEF $\leq 55-60 \%$ ).

The treatment effect across the EF continuum was also observed in the CHARM clinical program. As in PARAGON-HF, there was a potential benefit in favor of candesartan versus placebo in patients with an EF lower than $53 \% .^{20}$ This effect was also observed in a TOPCAT post-hoc analysis. ${ }^{21}$ Again, these data enhance the understanding of HFpEF but also raise questions about how we have been interpreting and diagnosing $\mathrm{HF}$, and whether a broader range of patients (e.g., LVEF < 35\%) could benefit from neurohormonal modulation. Despite this, there are no conclusive definitions on mid-range EF, where there probably be already disease progression and contractile impairment.

The PARAGON-HF is part of the sacubitril/valsartan clinical development program and provide us with another piece in the puzzle of neprilisin/ RAS inhibition in the complex scenario of HF syndrome. The study includes the assessment of the safety and efficacy of sacubitril/valsartan in different scenarios of HF including recently decompensated patients, across the spectrum of HF ejection fraction, pediatric HF patients and Chagas cardiomyopathy.

In addition, the PARALLAX-HF trial ${ }^{22}$ will include patients with $\mathrm{LVEF} \geq 40 \%$ and complete the EF continuum analysis. Soon expected is the PARADISE-MI trial, ${ }^{23}$ that will evaluate the safety and efficacy of sacubitril/valsartan versus ramipril in patients who have recently suffered a myocardial infarction. The study volunteers will not necessarily have a LVEF $<40 \%$, as long as they have signs of pulmonary congestion requiring intravenous treatment with diuretics, vasodilators, vasopressors and/ or inotropes, during the index hospitalization. ${ }^{23}$ These new trials will bring new perspectives and possible therapeuthic options for patients with cardiovascular diseases associated with high morbidity and mortality .

\section{Author contributions}

Conception and design of the research: JFK Saraiva. Writing of the manuscript: JFK Saraiva, Oliveira IBD.

\section{Potential Conflict of Interest}

José Francisco Saraivais investigator in clinical trials mentioned in the paper. Isadora de Oliveira is medical affairs role in a company that may direct or indirectly benefit from this publication.

\section{Sources of Funding}

There were no external funding sources for this study.

\section{Study Association}

This study is not associated with any thesis or dissertation work.

\section{Ethics approval and consent to participate}

This article does not contain any studies with human participants or animals performed by any of the authors.

\section{References}

1. Dunlay SM, Roger VL, Redfield MM. Epidemiology of heart failure with preserved ejection fraction. Nat Rev Cardiol. 2017;14(10):591-602.

2. Ponikowski P, Voors AA, Anker SD, Bueno H, Cleland JG, Coats AJ, et al. 2016 ESC Guidelines for the diagnosis and treatment of acute and chronic heart failure: The Task Force for the diagnosis and treatment of acute and chronic heart failure of the European Society of Cardiology (ESC). Developed with the special contribution of the Heart Failure Association (HFA) of the ESC. Eur J Heart Fail. 2016;18(8):891-975.

3. Comitê Coordenador da Diretriz de Insuficiência Cardíaca; Rohde LEP, Montera MW, Bocchi EA, Clausell NO, Albuquerque DC de, Rassi S, et al. Diretriz Brasileira de Insuficiência Cardíaca Crônica e Aguda. Arq Bras Cardiol .111(3):436-539.
4. Lam CSP, Gamble GD, Ling LH, Sim D, Leong KTG, Yeo PSD, et al. Mortality associated with heart failure with preserved vs. reduced ejection fraction in a prospective international multi-ethnic cohort study. Eur Heart J. 2018;39(20):1770-80.

5. Owan TE, Hodge DO, Herges RM, Jacobsen SJ, Roger VL, Redfield MM. Trends in Prevalence and Outcome of Heart Failure with Preserved Ejection Fraction. N Engl J Med. 2006;355(3):251-9.

6. Gerber Y, Weston SA, Redfield MM, Chamberlain AM, Manemann SM, Jiang $R$, et al. A contemporary appraisal of the heart failure epidemic in Olmsted County, Minnesota, 2000 to 2010. JAMA Intern Med. 2015;175(6):996-1004. 
7. Reddy YNV, Carter RE, Obokata M, Redfield MM, Borlaug BA. A Simple, Evidence-Based Approach to Help Guide Diagnosis of Heart Failure With Preserved Ejection Fraction. Circulation. 2018;138(9):861-70.

8. Lam CSP, Voors AA, de Boer RA, Solomon SD, van Veldhuisen DJ. Heart failure with preserved ejection fraction: from mechanisms to therapies. Eur Heart J. 2018;39(30):2780-92.

9. Shah SJ, Kitzman DW, Borlaug BA, van Heerebeek L, Zile MR, Kass DA, et al. Phenotype-Specific Treatment of Heart Failure With Preserved Ejection Fraction: A Multiorgan Roadmap. Circulation. 2016;134(1):73-90.

10. Pitt B, Pfeffer MA, Assmann SF, Boineau R, Anand IS, Claggett B, et al. Spironolactone for heart failure with preserved ejection fraction. N Engl J Med. 2014;370(15):1383-92.

11. Yusuf S, Pfeffer MA, Swedberg K, Granger CB, Held P, McMurray JJ, et al. Effects of candesartan in patients with chronic heart failure and preserved left-ventricular ejection fraction: the CHARM-Preserved Trial. Lancet. 2003;;362(9386):777-81.

12. Massie BM, Carson PE, McMurray JJ, Komajda M, McKelvie R, Zile MR, et al. Irbesartan in patients with heart failure and preserved ejection fraction. N Engl J Med. 2008;359(23):2456-67.

13. Cleland JG, Tendera M, Adamus J, Freemantle N, Polonski L, Taylor J. The perindopril in elderly people with chronic heart failure (PEP-CHF) study. Eur Heart J. 2006;27(19):2338-45.

14. Kotecha D, Lam CSP, Van Veldhuisen DJ, Van Gelder IC, Voors AA, Rienstra M. Heart Failure With Preserved Ejection Fraction and Atrial Fibrillation. J Am Coll Cardiol. 2016 Nov;68(20):2217-28.

15. McMurray JJ, Packer M, Desai AS, Gong J, Lefkowitz MP, Rizkala AR, et al. Angiotensin-neprilysin inhibition versus enalapril in heart failure. N Engl J Med. 2014;371(11):993-1004.

16. Solomon SD, Zile M, Pieske B, Voors A, Shah A, Kraigher-Krainer E, et al. The angiotensin receptor neprilysin inhibitor LCZ696 in heart failure with preserved ejection fraction: a phase 2 double-blind randomised controlled trial. Lancet. 2012;380(9851):1387-95.
17. Solomon SD, Rizkala AR, Lefkowitz MP, Shi VC, Gong J, Anavekar $\mathrm{N}$, et al. Baseline Characteristics of Patients With Heart Failure and Preserved Ejection Fraction in the PARAGON-HF Trial. Circ Heart Fail.. 2018;11(7):e004962.

18. Solomon SD, McMurray JJV, Anand IS, Ge J, Lam CSP, Maggioni AP, et al. Angiotensin-Neprilysin Inhibition in Heart Failure with Preserved Ejection Fraction. N Engl J Med. 2019;381(17):1609-20.

19. McMurray JJV, Jackson AM, Lam CSP, Redfield MM, Anand IS, Ge J, et al. Effects of Sacubitril-Valsartan, versus Valsartan, in Women Compared to Men with Heart Failure and Preserved Ejection Fraction: Insights from PARAGON-HF. Circulation. 2019 Nov 17; [Epub ahead of print].

20. Lund LH, Claggett B, Liu J, Lam CS, Jhund PS, Rosano GM, et al. Heart failure with mid-range ejection fraction in CHARM: characteristics, outcomes and effect of candesartan across the entire ejection fraction spectrum. Eur J Heart Fail. 2018;20(8):1230-9.

21. Solomon SD, Claggett B, Lewis EF, Desai A, Anand I, Sweitzer NK, et al. Influence of ejection fraction on outcomes and efficacy of spironolactone in patients with heart failure with preserved ejection fraction.Eur Heart J. 2016;37(5):455-62

22. ClinicalTrials.gov [Internet]. Bethesda (MD): National Library of Medicine (US). Identifier NCT03066804, A Randomized, Doubleblind Controlled Study Comparing LCZ696 to Medical Therapy for Comorbidities in HFpEF Patients (PARALLAX) [cited 2019 Dec 06]. Available from: https://clinicaltrials.gov/ct2/show/NCT03066804?id=N CT03066804\&draw=2\&rank=1\&load=cart.

23. ClinicalTrials.gov [Internet]. Bethesda (MD): National Library of Medicine (US). Identifier: NCT02924727, Prospective ARNI vs ACE Inhibitor Trial to DetermIne Superiority in Reducing Heart Failure Events After MI (PARADISE-MI) [cited 2019 Dec 06]. Available from: https:/clinicaltrials.gov/ct2/show/NCT02924727?term=PARADISEMI\&draw=2\&rank=1. 